\title{
Potential Vertical Movement of Large Heat-Generating Waste Packages in Salt
}

\author{
Daniel J. Clayton \\ Advanced Nuclear Fuel Cycle Technologies \\ Mario J. Martinez \\ Microscale Science and Technology \\ Ernest L. Hardin \\ Applied Systems Analysis and Research \\ Sandia National Laboratories \\ PO Box 5800 \\ Albuquerque, New Mexico 87185-0747
}

Sandia National Laboratories is a multi-program laboratory managed and operated by Sandia Corporation, a wholly owned subsidiary of Lockheed Martin Corporation, for the U.S. Department of Energy's National Nuclear Security Administration under contract DE-AC04-94AL85000.

Approved for public release; further dissemination unlimited. 


\section{Sandia National Laboratories}




\section{Issued by Sandia National Laboratories, operated for the United States Department of Energy by Sandia Corporation.}

NOTICE: This report was prepared as an account of work sponsored by an agency of the United States Government. Neither the United States Government, nor any agency thereof, nor any of their employees, nor any of their contractors, subcontractors, or their employees, make any warranty, express or implied, or assume any legal liability or responsibility for the accuracy, completeness, or usefulness of any information, apparatus, product, or process disclosed, or represent that its use would not infringe privately owned rights. Reference herein to any specific commercial product, process, or service by trade name, trademark, manufacturer, or otherwise, does not necessarily constitute or imply its endorsement, recommendation, or favoring by the United States Government, any agency thereof, or any of their contractors or subcontractors. The views and opinions expressed herein do not necessarily state or reflect those of the United States Government, any agency thereof, or any of their contractors.

Printed in the United States of America. This report has been reproduced directly from the best available copy.

Available to DOE and DOE contractors from

U.S. Department of Energy

Office of Scientific and Technical Information

P.O. Box 62

Oak Ridge, TN 37831

Telephone: $\quad$ (865) 576-8401

Facsimile: (865) 576-5728

E-Mail: reports@adonis.osti.gov

Online ordering: http://www.osti.gov/bridge

Available to the public from

U.S. Department of Commerce

National Technical Information Service

5285 Port Royal Rd.

Springfield, VA 22161

Telephone: $\quad$ (800) 553-6847

Facsimile: (703) 605-6900

E-Mail: $\quad$ orders@ntis.fedworld.gov

Online order: $\quad$ http://www.ntis.gov/help/ordermethods.asp?loc=7-4-0\#online

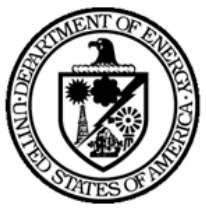


SAND2013-3596

Unlimited Release

Printed May 2013

\title{
POTENTIAL VERTICAL MOVEMENT OF LARGE HEAT- GENERATING WASTE PACKAGES IN SALT
}

\begin{abstract}
With renewed interest in disposal of heat-generating waste in bedded or domal salt formations, scoping analyses were conducted to estimate rates of waste package vertical movement. Vertical movement is found to result from thermal expansion, from upward creep or heave of the near-field salt, and from downward buoyant forces on the waste package. A two-pronged analysis approach was used, with thermal-mechanical creep modeling, and coupled thermal-viscous flow modeling. The thermal-mechanical approach used well-studied salt constitutive models, while the thermal-viscous approach represented the salt as a highly viscous fluid. The Sierra suite of coupled simulation codes was used for both approaches. The waste package in all simulations was a right-circular cylinder with the density of steel, in horizontal orientation. A time-decaying heat generation function was used to represent commercial spent fuel with typical burnup and 50-year age.

Results from the thermal-mechanical base case showed approximately $27 \mathrm{~cm}$ initial uplift of the package, followed by gradual relaxation closely following the calculated temperature history. A similar displacement history was obtained with the package density set equal to that of salt. The slight difference in these runs is attributable to buoyant displacement (sinking) and is on the order of $1 \mathrm{~mm}$ in 2,000 years. Without heat generation the displacement stabilizes at a fraction of millimeter after a few hundred years. Results from thermal-viscous model were similar, except that the rate of sinking was constant after cooldown, at approximately $0.15 \mathrm{~mm}$ per $1,000 \mathrm{yr}$. In summary, all calculations showed vertical movement on the order of $1 \mathrm{~mm}$ or less in 2,000 yr, including calculations using well-established constitutive models for temperature-dependent salt deformation. Based on this finding, displacement of waste packages in a salt repository is not a significant repository performance issue.
\end{abstract}


Potential Vertical Movement of Large Heat-Generating Waste Packages in Salt May 2013

\section{ACKNOWLEDGEMENTS}

Sandia National Laboratories is a multi-program laboratory managed and operated by Sandia Corporation, a wholly owned subsidiary of Lockheed Martin Corporation, for the U.S. Department of Energy's National Nuclear Security Administration under Contract DEAC04-94AL85000. 
Potential Vertical Movement of Large Heat-Generating Waste Packages in Salt

May 2013

\section{TABLE OF CONTENTS}

Potential Vertical Movement of Large Heat-Generating Waste Packages in Salt ..... 3

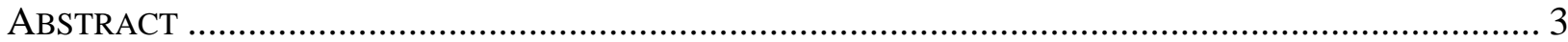

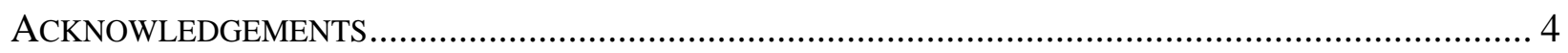

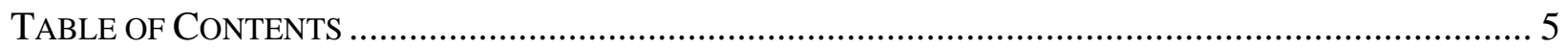

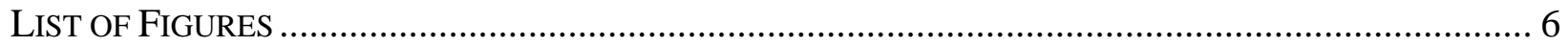

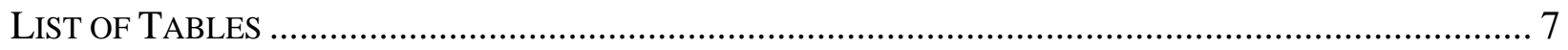

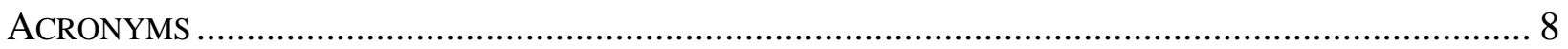

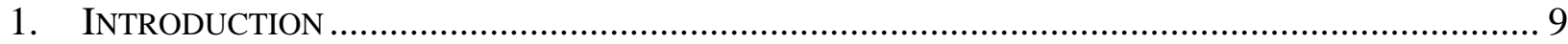

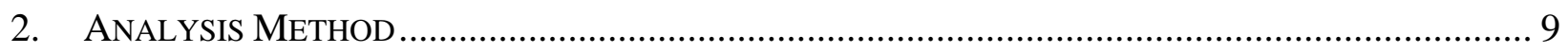

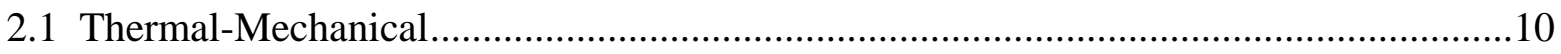

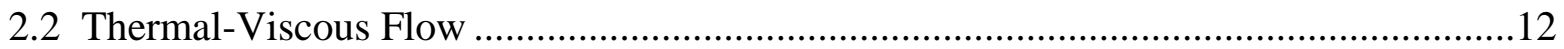

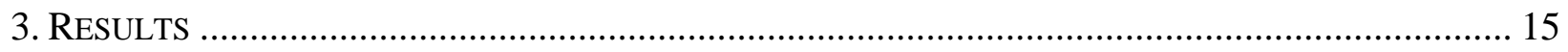

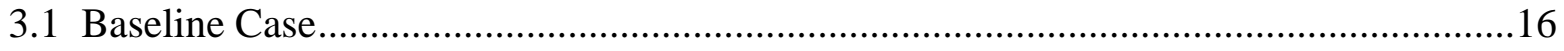

3.2 Reduced Waste Package Density .......................................................................17

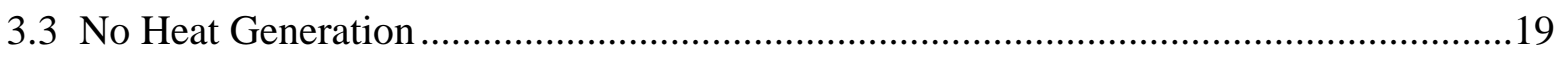

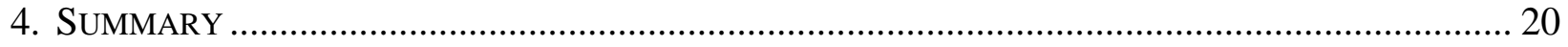

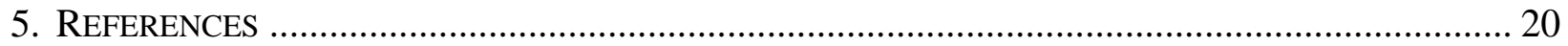




\section{LIST OF FIGURES}

Figure 1. Schematic of waste package embedded in intact salt.............................................. 9

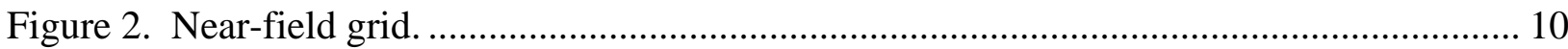

Figure 3. Decay curve used in the thermal analysis.............................................................. 11

Figure 4. Effective viscosity versus temperature for intact salt calculated using the M-D creep model (Munson 1997)................................................................................................. 13

Figure 5. Horizontal waste package vertical settling velocity versus salt effective viscosity..... 15

Figure 6. Horizontal waste package vertical settling velocity versus salt temperature.............. 15

Figure 7. Maximum temperature in waste package versus time.............................................. 16

Figure 8. Thermal-mechanical modeling, baseline case, waste package vertical

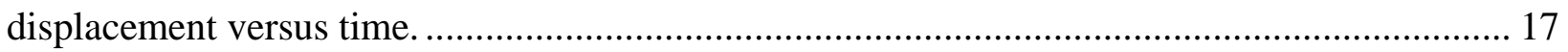

Figure 9. Thermal-viscous flow modeling, baseline case, waste package vertical

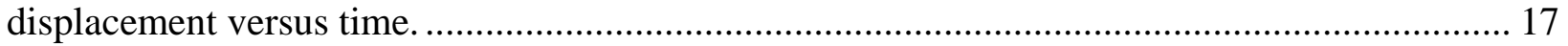

Figure 10. Thermal-mechanical modeling, reduced density, waste package vertical

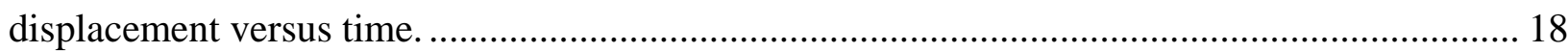

Figure 11. Comparison of thermal-mechanical modeling, baseline and reduced density, waste package vertical displacement versus time.

Figure 12. Thermal-mechanical modeling, no heat generation, waste package vertical displacement versus time.

Figure 13. Thermal-viscous flow modeling, no heat generation, waste package vertical displacement versus time. 
Potential Vertical Movement of Large Heat-Generating Waste Packages in Salt

May 2013

\section{LIST OF TABLES}

Table 1. Thermal properties for the waste and salt.......................................................... 11

Table 2. Mechanical properties used for the waste................................................................. 12

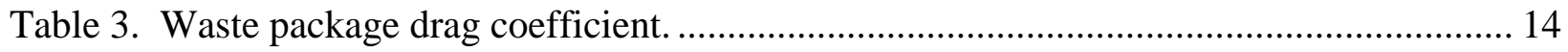


Potential Vertical Movement of Large Heat-Generating Waste Packages in Salt May 2013

\section{ACRONYMS}

GW-d/MT Gigawatt (thermal)-day per metric ton uranium

kW kilowatt

M-D Multi-mechanism Deformation model

$\mathrm{Pa} \quad$ Pascal $\left(\mathrm{Nt} / \mathrm{m}^{2}\right)$

Pa-s Pascal-seconds

R\&D Research \& Development 


\section{INTRODUCTION}

With renewed interest in disposal of heat generating waste in salt, feasibility studies for disposal of large packages in a generic salt repository are underway. One aspect of these studies is to investigate the potential vertical movement of the waste packages. Intact salt creeps at a rate that depends on shear stress and temperature. Given that large packages could weigh up to 130 tons (depending on capacity and shielding requirements) and generate near-field temperatures up to $200{ }^{\circ} \mathrm{C}$, it is possible that the waste packages could move significantly over thousands of years. This memo discusses preliminary calculations completed in March, 2013, that are expected to become part of a deliverable for the Used Fuel Disposition R\&D campaign, later in fiscal-year 2013.

\section{ANALYSIS METHOD}

A two-pronged approach was used in this investigation. Potential vertical movement was analyzed using coupled thermal-mechanical modeling and coupled thermal-viscous flow modeling. The thermal-mechanical modeling used salt constitutive models, while the thermalviscous flow modeling assumed that the salt acts like a highly viscous fluid. Both approaches simulated a three-dimensional, 5-m long, 2-m diameter waste package embedded in intact salt (Figure 1).

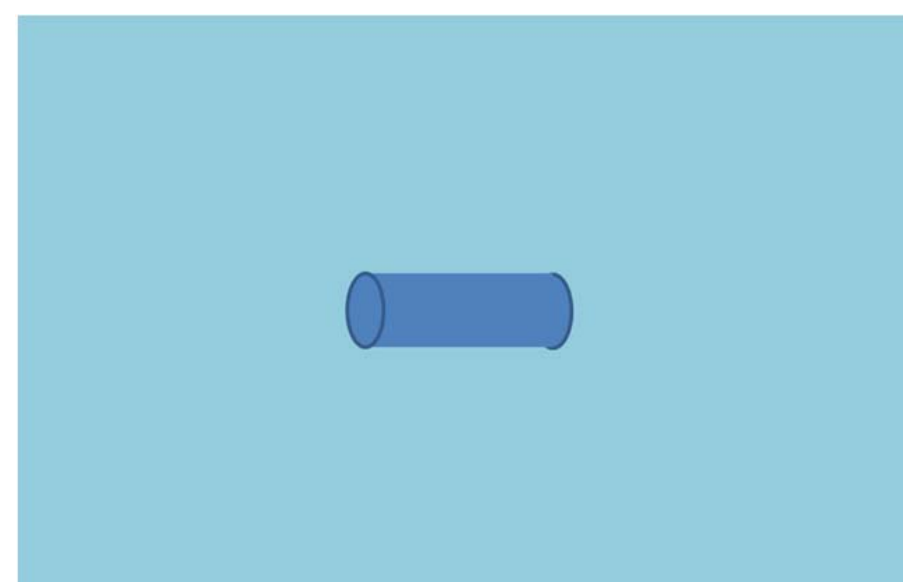

Figure 1. Schematic of waste package embedded in intact salt.

The grid was constructed using 3-D hexagonal elements. A slice of the grid is shown below in Figure 2. The green portion represents the cylindrical waste package, while the blue portion represents the intact salt. The intact salt was modeled as a bed $60 \mathrm{~m}$ by $60 \mathrm{~m}$ by $100 \mathrm{~m}$ with the waste package in the center. Symmetry conditions were used on the four sides of the model and boundary conditions were used on the top and bottom of the domain to simulate a waste package depth of $\sim 600 \mathrm{~m}$. 


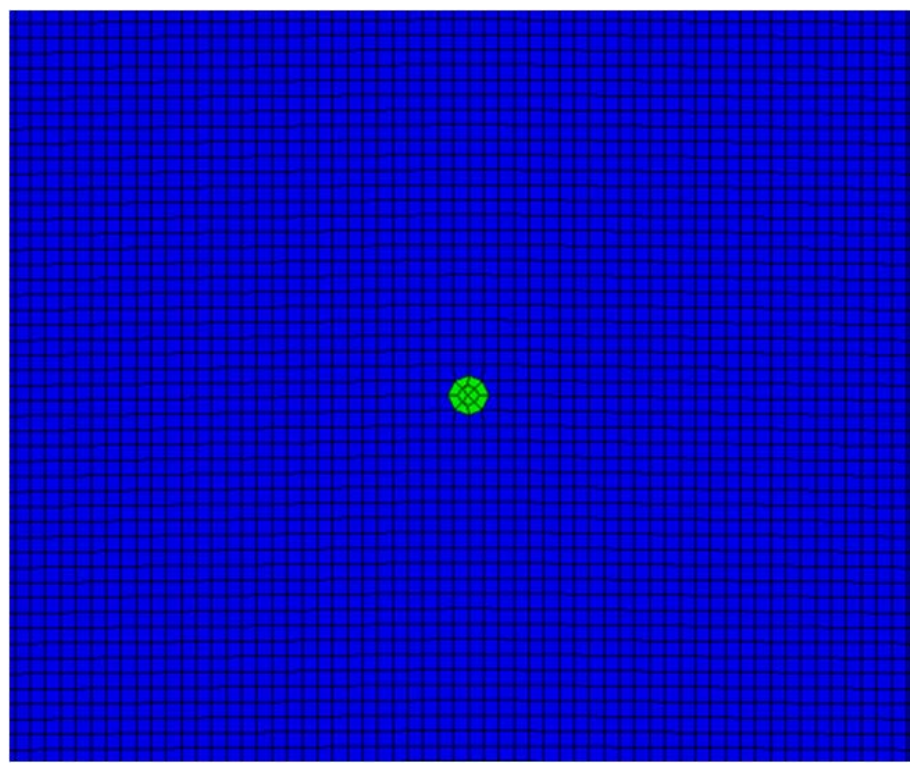

Figure 2. Near-field grid.

\subsection{Thermal-Mechanical}

Coupled thermal-mechanical calculations were carried out by coupling thermal and mechanical codes through an interface that allows state variables such as temperature and displacement to be passed from one code to the other. The combined code is executed using output from the thermal code as input to the mechanical code, and vice versa. To do this, we used two available codes in the Sierra tool set: Aria (a Galerkin finite element based program for solving coupled-physics problems described by systems of partial differential equations) and Adagio (a Lagrangian mechanical modeling program with special provisions for modeling salt deformation). A third code, Arpeggio, was used to couple the two codes together and control the simulations.

For the thermal analysis, a convective-type boundary condition was applied to the top and bottom of the model to simulate conductive heat transport into the host rock above and below the repository. All materials were assumed to be initially at $25^{\circ} \mathrm{C}$. A thermal load of $13 \mathrm{~kW}$ was applied at time zero uniformly throughout the waste package, with a decay response specified as a function of time (Figure 3). The decay curve used was chosen to simulate $40 \mathrm{GW}-\mathrm{d} / \mathrm{MT}$ burnup, pressurized water reactor waste with age of 50 years out-of-reactor at the time of emplacement. 
Potential Vertical Movement of Large Heat-Generating Waste Packages in Salt May 2013

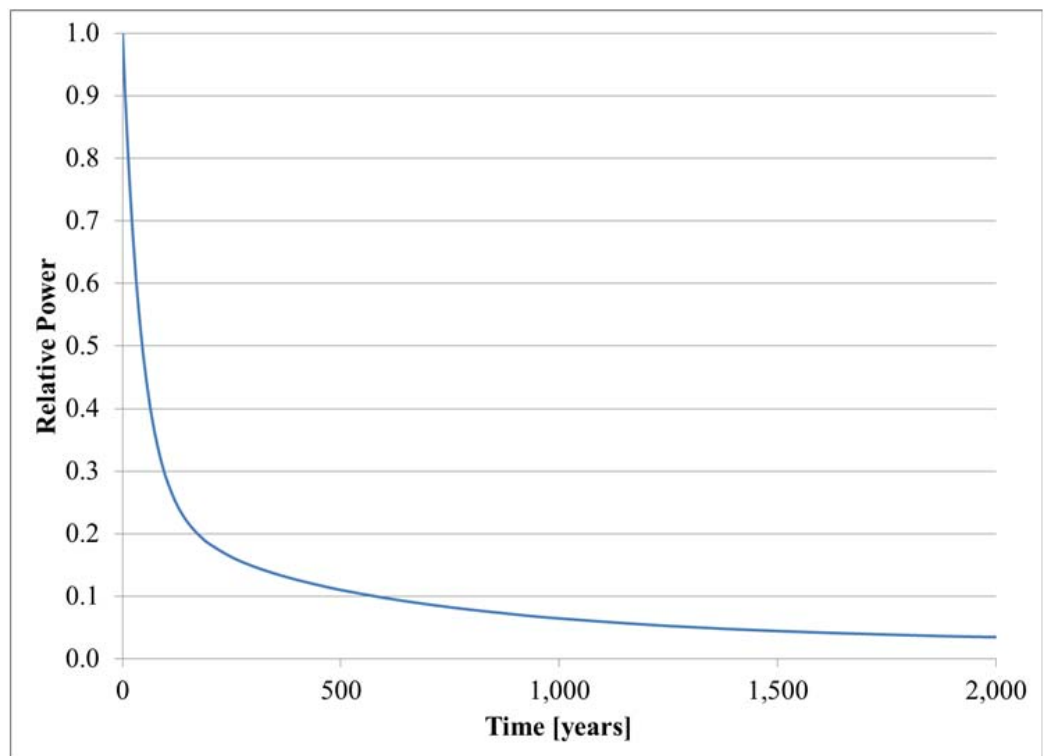

Figure 3. Decay curve used in the thermal analysis.

The temperature dependent thermal conductivity of intact salt used in the analysis is given in the following equation

$$
\lambda_{\text {salt }}(T)=\lambda_{300}\left(\frac{300}{T}\right)^{\gamma}
$$

where:

$$
\begin{array}{ll}
\lambda_{300} & =\text { material constant, } 5.4[\mathrm{~W} / \mathrm{m} / \mathrm{K}] \\
\gamma & =\text { material constant }=1.14 \\
T & =\text { temperature }[\mathrm{K}] .
\end{array}
$$

A summary of the thermal material properties assumed for the waste and intact salt are shown in Table 1.

Table 1. Thermal properties for the waste and salt

\begin{tabular}{|l|c|c|c|}
\hline Material & $\begin{array}{c}\text { Thermal } \\
\text { Conductivity } \\
(\mathbf{W} / \mathbf{m} / \mathbf{K})\end{array}$ & $\begin{array}{c}\text { Specific } \\
\text { Heat } \\
(\mathbf{J} / \mathbf{k g} / \mathbf{K})\end{array}$ & $\begin{array}{c}\text { Density } \\
\mathbf{( k g / \mathbf { m } ^ { 3 } )}\end{array}$ \\
\hline Waste & 53 & 500 & 7,854 \\
\hline Intact Salt & Equation (1) & 931 & 2,160 \\
\hline
\end{tabular}

For the mechanical analysis, boundary conditions were set so that horizontal displacements were zero along the vertical boundaries, and both horizontal and vertical displacements were zero along the bottom. Mechanical loads acting on the model consisted of an overburden pressure applied to the top representing an alcove depth of $\sim 600 \mathrm{~m}$. The domain was initialized with 
Potential Vertical Movement of Large Heat-Generating Waste Packages in Salt May 2013

lithostatic stresses corresponding to depth. The intact salt was modeled using the multimechanism-deformation (M-D) creep model (Munson 1997) and the waste package was assumed to respond elastically using the properties of steel shown in Table 2.

Table 2. Mechanical properties used for the waste.

\begin{tabular}{|l|c|c|c|}
\hline Material & $\begin{array}{c}\text { Young's } \\
\text { Modulus } \\
\text { (Pa) }\end{array}$ & $\begin{array}{c}\text { Poisson's } \\
\text { Ratio }\end{array}$ & $\begin{array}{c}\text { Thermal } \\
\text { Expansion } \\
\left.\mathbf{( K}^{-\mathbf{1}}\right)\end{array}$ \\
\hline Heater & $2.0 \mathrm{E} 11$ & 0.3 & $1.0 \mathrm{E}-5$ \\
\hline
\end{tabular}

\subsection{Thermal-Viscous Flow}

Coupled thermal-viscous flow calculations were carried out using Aria (a Galerkin finite element based program for solving coupled-physics problems described by systems of partial differential equations). Aria incorporates both the thermal and viscous flow models, and was the only code needed for these calculations. For the purposes of this analysis, the salt is treated as a viscous fluid with temperature-dependent viscosity. For the thermal part of the calculations, the same boundary conditions and thermal properties used in the thermal-mechanical modeling were used in the thermal-viscous flow modeling. The viscosity was derived from the salt constitutive models used in the mechanical calculations.

The viscosity of a fluid can be defined by the relationship

$$
\tau=\mu \frac{d u}{d y}
$$

where $\tau$ is the shear stress and $u$ is the velocity in the $\mathrm{x}$-direction. The quantity $d u / d y$ is a velocity gradient and can be interpreted as a strain rate. Salt constitutive models give a relationship between applied stress and strain rate. Using the M-D creep model stress/strain rate relationship and solving for viscosity gives the following relationship

$$
\mu=\frac{\tau}{A_{1} e^{\left(\frac{-Q_{1}}{R T}\right)\left(\frac{\sigma}{G}\right)^{n_{1}}+A_{2} e^{\left(\frac{-Q_{2}}{R T}\right)}\left(\frac{\sigma}{G}\right)^{n_{2}}+H\left(\sigma-\sigma_{0}\right)\left[B_{1} e^{\left(\frac{-Q_{1}}{R T}\right)}+B_{2} e^{\left(\frac{-Q_{2}}{R T}\right)}\right] \times \sinh \left[\frac{q\left(\sigma-\sigma_{0}\right)}{G}\right]}}
$$

where the As and $B$ s are constants, $Q$ s are activation energies, $T$ is the absolute temperature, $R$ is the universal gas constant, $G$ is the shear modulus, $\sigma$ is the generalized stress, $n s$ are the stress exponents, $H$ is the Heaviside step function with the argument $\left(\sigma-\sigma_{0}\right), q$ is the stress constant and $\sigma_{0}$ is the stress limit of the dislocation slip mechanism. The force on the waste package due to buoyancy can be calculated by multiplying the waste package volume by the difference in density between the waste package and the salt, and the gravitational constant. The shear stress is then calculated by dividing the buoyant force of the waste package by the surface area of the waste package. The mean applied stress was calculated by dividing the force of the waste package by the projected area. For these calculations, the smallest projected area, with the waste package in the vertical position, was used so as not to underestimate the mean applied stress. The applied stress was then assumed to be three times the mean applied stress. For the 5-m long, 2-m diameter waste package with $7,854 \mathrm{~kg} / \mathrm{m}^{3}$ density (density of solid steel), the shear and 
applied stresses were calculated to be 3.21E4 Pa and 1.15E6 Pa, respectively. Using these stress values and salt constitutive model parameters from Munson (1997), the effective viscosity of the intact salt as a function temperature is

$$
\mu=4.74 E 11 /\left[8.37 E 7 \cdot e^{\wedge}(-1.26 E 4 / T)+e^{\wedge}(-5.03 E 3 / T)\right]
$$

where $T$ is the temperature in Kelvin. A plot of effective viscosity versus temperature is shown in Figure 4.

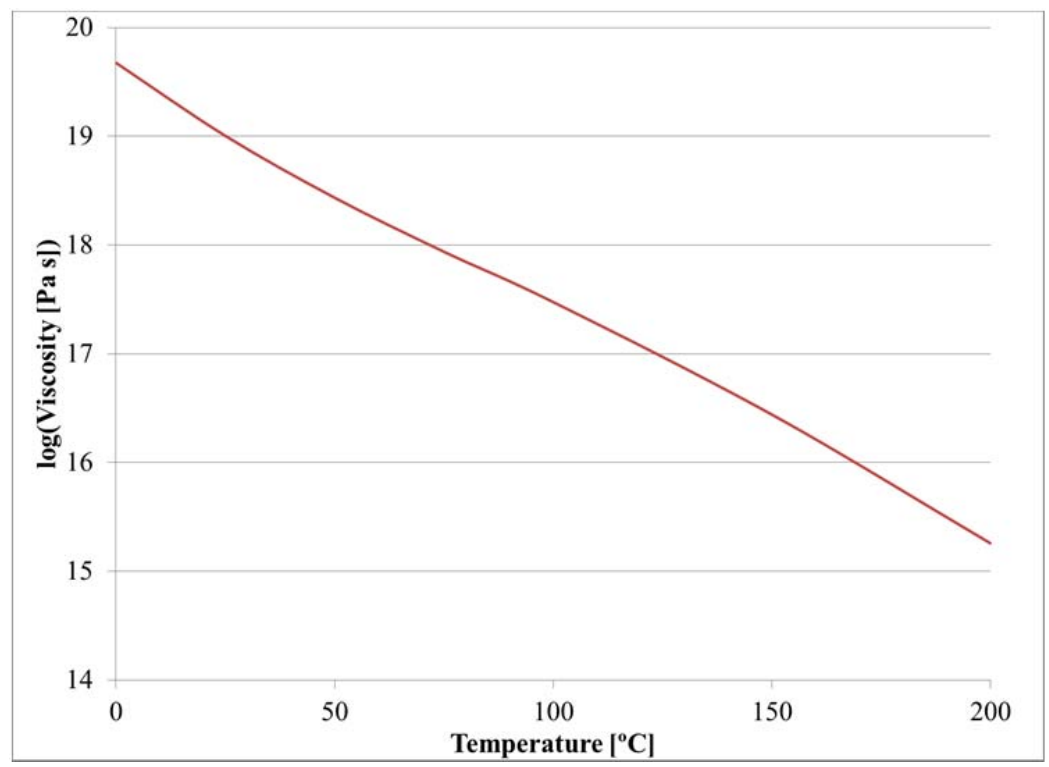

Figure 4. Effective viscosity versus temperature for intact salt calculated using the M-D creep model (Munson 1997).

An initial estimate of the settling velocity of the waste package in the absence of heating is useful to establish the scale of the motion and also for verification of numerical calculations of the heated problem to follow. The slow (creeping flow) settling velocity of a fluid sphere of radius $a$, density $\rho_{\text {can }}$, viscosity $\mu_{\text {can }}$ in a fluid of density $\rho$ and viscosity $\mu$, can be determined based on the well-known Hadamard solution (see Batchelor 1967). By balancing viscous drag with the buoyant force on the fluid sphere, the steady settling speed can be determined:

$$
V=\frac{1}{3} \frac{a^{2} \rho g}{\mu}\left(\frac{\rho_{c a n}}{\rho}-1\right) \frac{\mu+\mu_{c a n}}{\mu+3 \mu_{c a n} / 2} .
$$

The settling velocity of a rigid sphere is recovered for $\mu_{\text {can }} / \mu>>1$. The drag on a rigid sphere moving at constant velocity $V$, is given by the well-known Stokes drag formula, $D=6 \pi a \mu V$. The steady settling velocity is computed by equating the drag on the sphere with the buoyant force exerted on the sphere by virtue of its density difference with the salt. 
By calculating the drag on the waste package, a similar procedure to compute its settling velocity can be developed. The waste package is a right circular cylinder of radius $a$ and length $L$. A drag coefficient is defined for the waste package moving at a speed of $U$ (small Reynolds number) as

$$
C_{D}=\frac{D_{c a n}}{\mu \bar{a} U}
$$

where we take the effective radius as $\bar{a}=V_{c a n}^{1 / 3}$, and $V_{c a n}=\pi a^{2} L$. The dimensionless settling velocity of the waste package can then be written as

$$
\frac{\mu U}{\rho g \bar{a}^{2}}=C_{D}^{-1}\left(\frac{\rho_{c a n}}{\rho}-1\right) .
$$

By computing the drag coefficient the settling velocity can be computed as a function of density ratio and fluid viscosity, for isothermal conditions. Numerical calculations of the drag coefficient were carried out for the waste package $(\bar{a}=2.504)$. The effective viscosity of the waste package was set to $1 \mathrm{e} 22 \mathrm{~Pa}-\mathrm{s}$ in the numerical calculations to essentially treat the waste package as rigid. Table 3 gives the drag coefficients computed for vertical movement of the waste package in horizontal (i.e. centerline axis is horizontal) and vertical orientations. The table also gives the drag on a rigid sphere of radius $1 \mathrm{~m}$ for comparison.

Table 3. Waste package drag coefficient.

\begin{tabular}{|c|c|}
\hline $\begin{array}{c}\text { Waste Package } \\
\text { Orientation }\end{array}$ & $\mathbf{C}_{\mathbf{D}}$ \\
\hline Horizontal & 13.4 \\
\hline Vertical & 12.4 \\
\hline Sphere & 11.7 \\
\hline
\end{tabular}

It is worthwhile to note that there is less drag on the waste package in the vertical orientation compared to the horizontal orientation. This suggests that given conditions favorable to buoyant motion the waste package would right itself into a vertical orientation, even when it starts out in the horizontal orientation.

Using the waste package dimensions, waste package and salt densities, and computed drag coefficient, the vertical settling velocity (positive downward) of a horizontal waste package as a function of viscosity can be calculated and is shown in (Figure 5). Using the temperature dependence of effective viscosity shown in equation 4, the vertical velocity as a function of temperature can be computed as shown in Figure 6 . 
Potential Vertical Movement of Large Heat-Generating Waste Packages in Salt May 2013

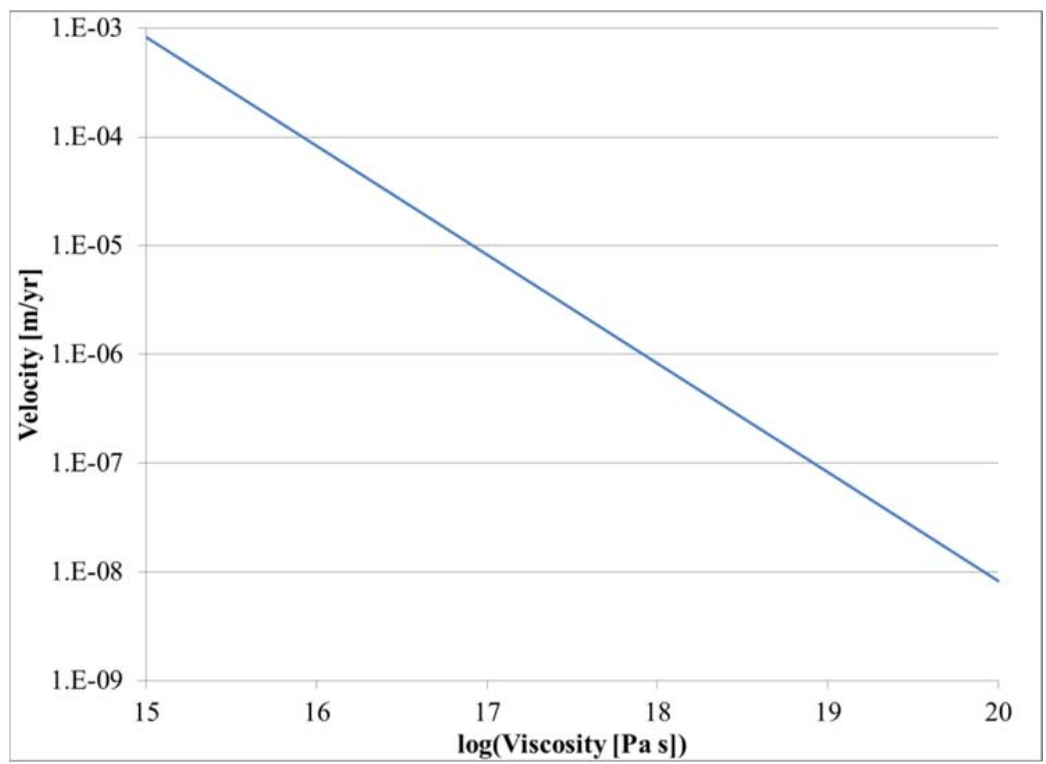

Figure 5. Horizontal waste package vertical settling velocity versus salt effective viscosity.

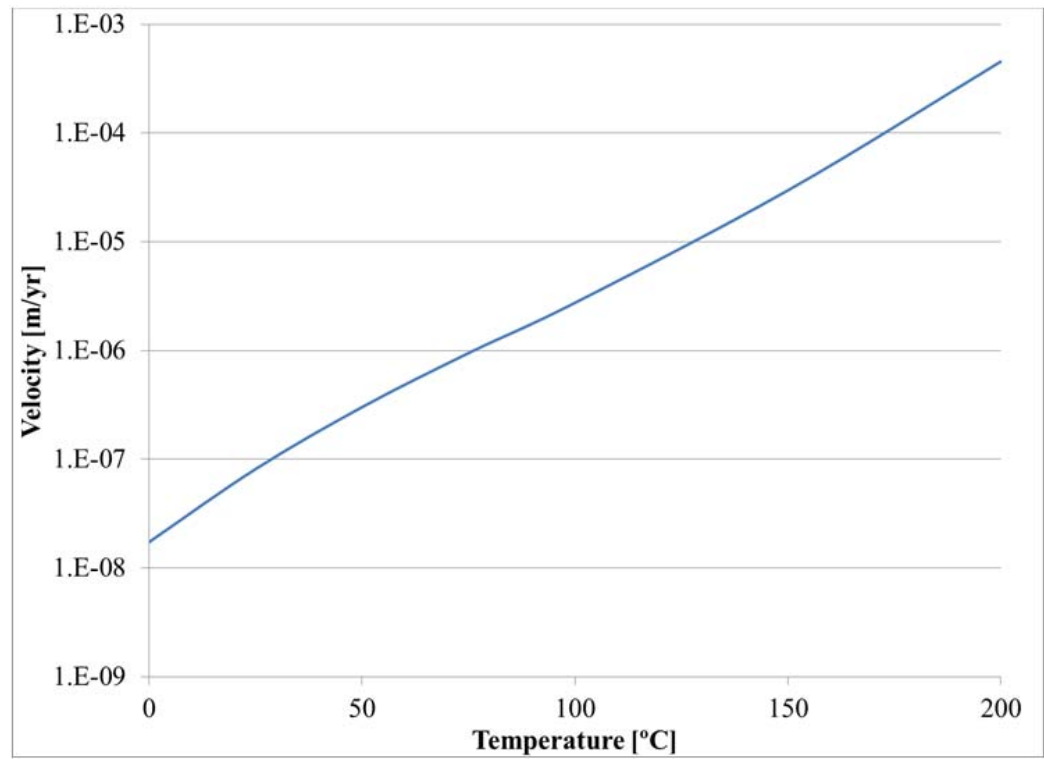

Figure 6. Horizontal waste package vertical settling velocity versus salt temperature.

\section{RESULTS}

Calculations with the heat generating waste package were conducted using both the thermalmechanical modeling and thermal-viscous flow modeling on the grid shown in Figure 2. To aid in the interpretation of the results, two additional cases were modeled; the first included heat generation and the density of the waste package was set equal to the salt, and the second did not include heat generation and maintained the original waste package density. The results for each case are discussed below. 


\subsection{Baseline Case}

The resulting temperature history of the salt at the waste package surface is shown in Figure 7. The waste package temperature history was the same for both the thermal-mechanical modeling and thermal-viscous flow modeling. The highest temperatures are within the waste package, with the salt temperature peaking at the waste/salt interface and decreasing with distance from the waste package. The peak waste package temperature of $180^{\circ} \mathrm{C}$ is reached at $\sim 16$ years with the temperature decreasing toward the initial temperature with time as the waste decays.

The resulting waste package vertical displacement history from thermal-mechanical modeling is shown in Figure 8. The vertical displacement appears to follow the temperature history. As the waste package and surrounding salt heat up, they expand causing uplift of the waste package and the surrounding salt. As the waste package and surrounding salt cool down and contract, they approach their original positions. From this calculation it is difficult to discern waste package displacement due to the density difference ("sinking") when compared with the movement due to the thermal expansion. Movement of the waste package relative to the surrounding salt is better discerned from the reduced density case discussed below.

The resulting waste package vertical displacement history from the thermal-viscous flow modeling is shown in Figure 9. The waste package sinks faster initially, corresponding to the increased temperatures, then slows down and continues to sink more slowly, with a total displacement of approximately $-0.5 \mathrm{~mm}$ at 2,000 years. The thermal-viscous flow modeling includes the change in density due to temperature, and tracks the waste package movement relative to the surrounding salt, so the sinking behavior is not masked by the overall displacement due to thermal expansion.

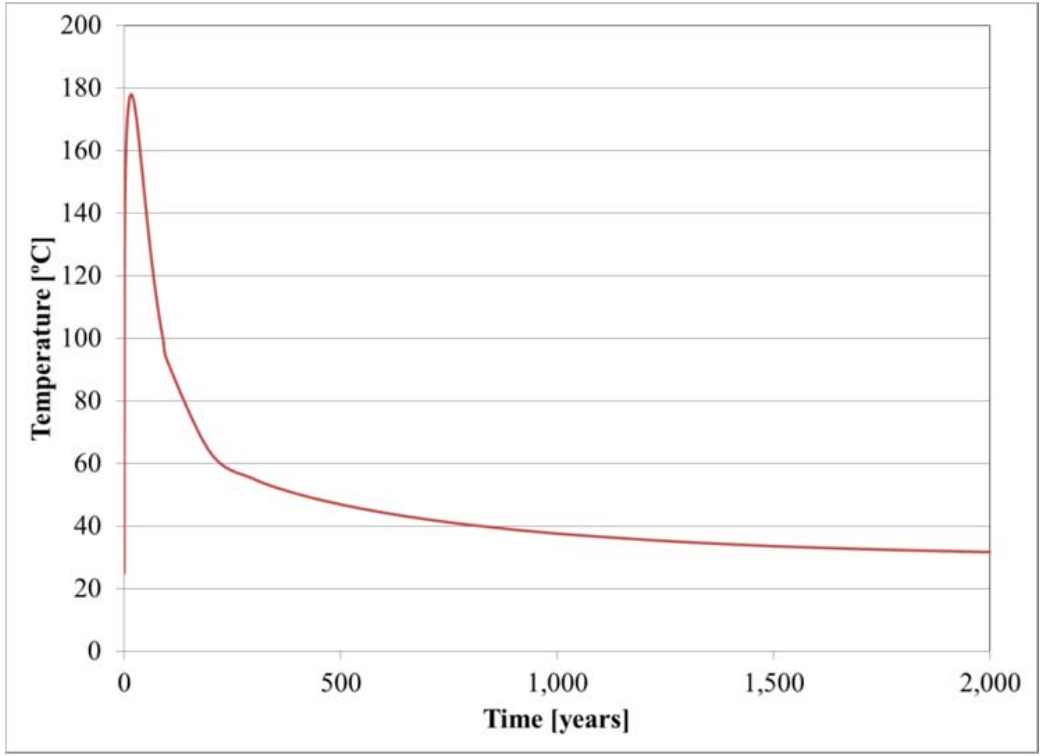

Figure 7. Maximum temperature in waste package versus time. 
Potential Vertical Movement of Large Heat-Generating Waste Packages in Salt May 2013

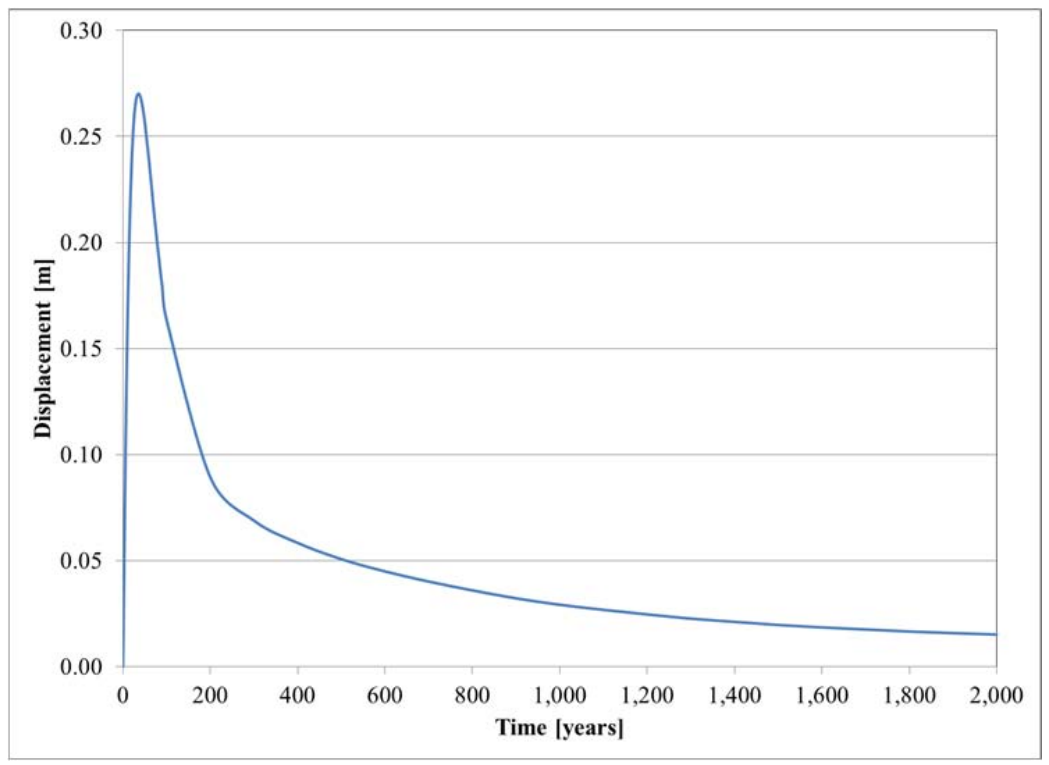

Figure 8. Thermal-mechanical modeling, baseline case, waste package vertical displacement versus time.

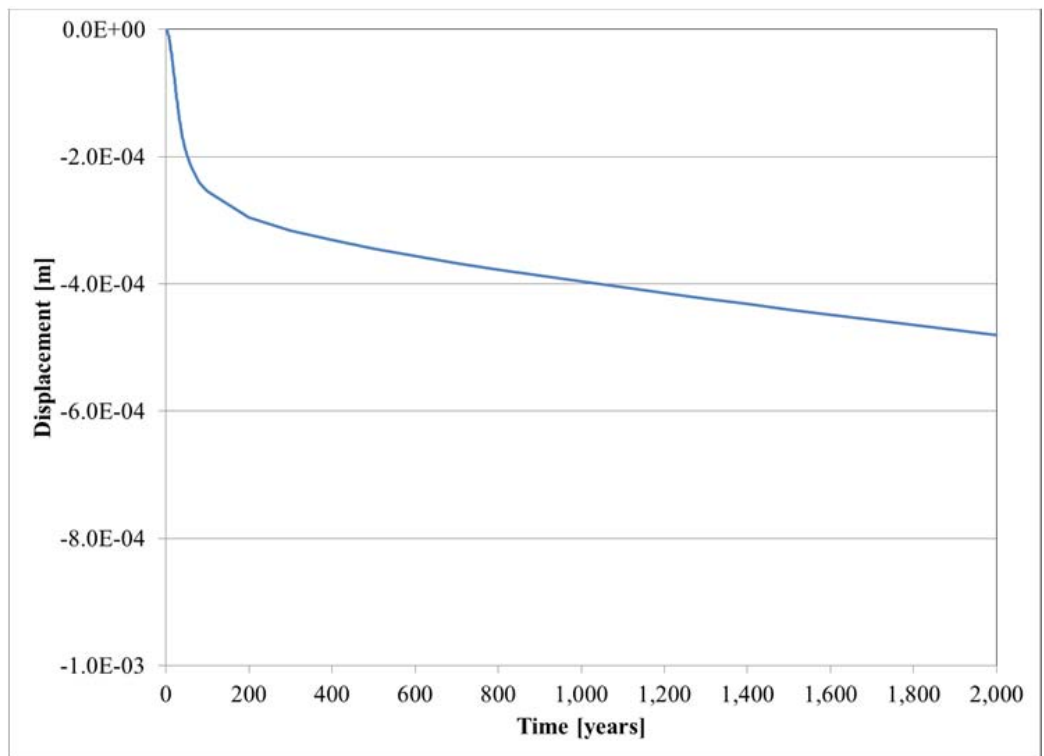

Figure 9. Thermal-viscous flow modeling, baseline case, waste package vertical displacement versus time.

\subsection{Reduced Waste Package Density}

To investigate the effect of waste package density on vertical displacement, a second case was evaluated in which the waste package density was reduced, and equal to the salt. The resulting waste package vertical displacement history from thermal-mechanical modeling is shown in 
Figure 10. It follows the same general trend as the baseline case. A comparison of the two vertical displacement histories is shown in Figure 11. The difference between the two curves at 2,000 years is $\sim 1.2 \mathrm{~mm}$, which compares with the value calculated from the thermal-viscous flow modeling. The thermal-viscous flow modeling of this case shows vertical displacement on the micron scale after 2,000 years, which is essentially no vertical displacement.

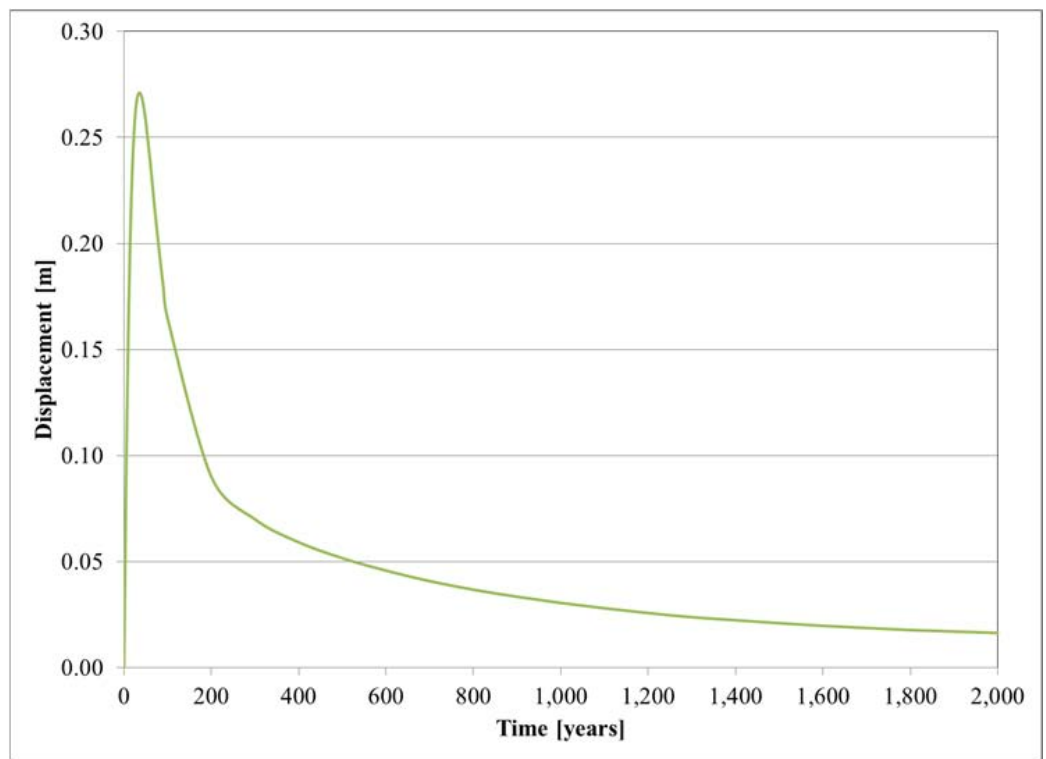

Figure 10. Thermal-mechanical modeling, reduced density, waste package vertical displacement versus time.

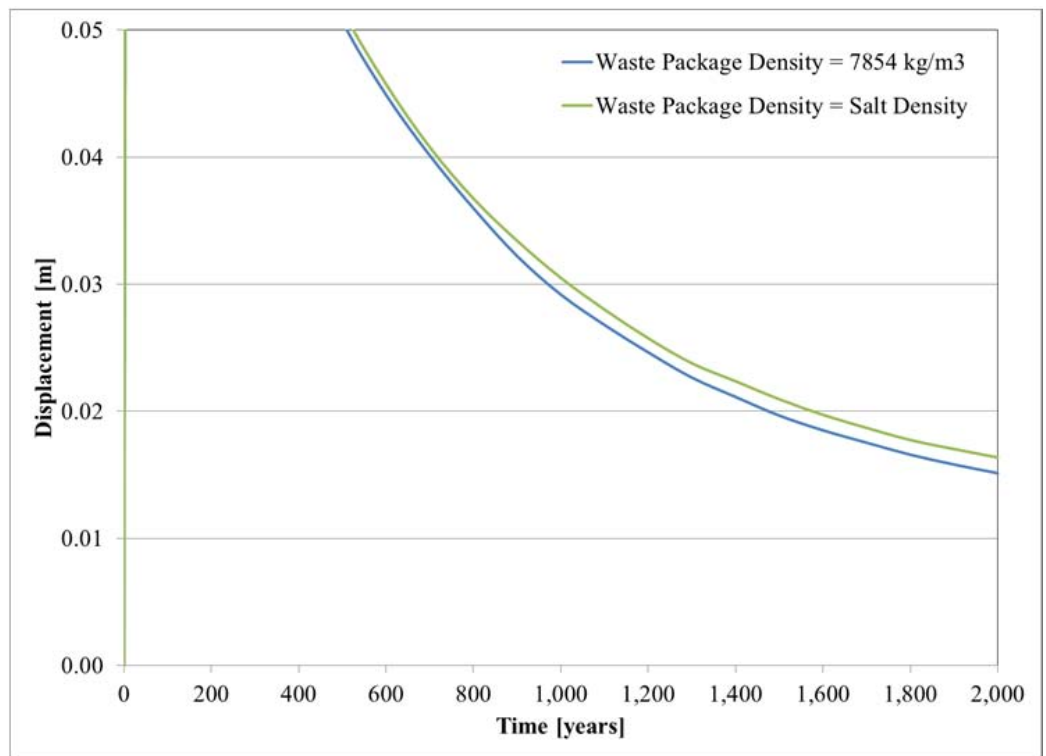

Figure 11. Comparison of thermal-mechanical modeling, baseline and reduced density, waste package vertical displacement versus time. 


\subsection{No Heat Generation}

To determine the effect of heat generation on the vertical displacement, a third case was computed that retained the waste package density contrast, but with no heat generation. The resulting waste package vertical displacement history from thermal-mechanical modeling is shown in Figure 12, while the thermal-viscous flow modeling results for the same conditions are shown in Figure 13. The thermal-mechanical results show a quick drop of the waste package, which then settles to about $-0.06 \mathrm{~mm}$ and remains nearly constant after $\sim 1,000$ years. The thermal-viscous flow modeling results show a constant downward velocity, with magnitude very similar to the analytical solution given in Figure 5, and with a final vertical displacement of approximately $-0.14 \mathrm{~mm}$ after 2,000 years. Without heat generation, vertical displacement is shown to be at least an order a magnitude smaller.

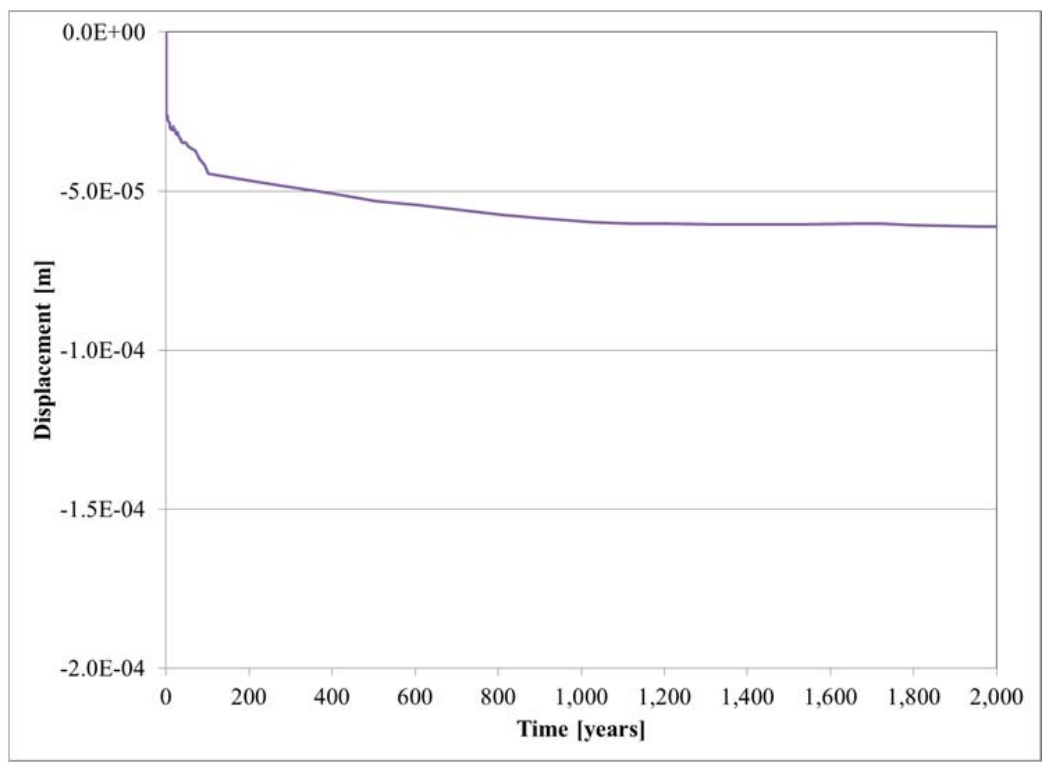

Figure 12. Thermal-mechanical modeling, no heat generation, waste package vertical displacement versus time. 
Potential Vertical Movement of Large Heat-Generating Waste Packages in Salt May 2013

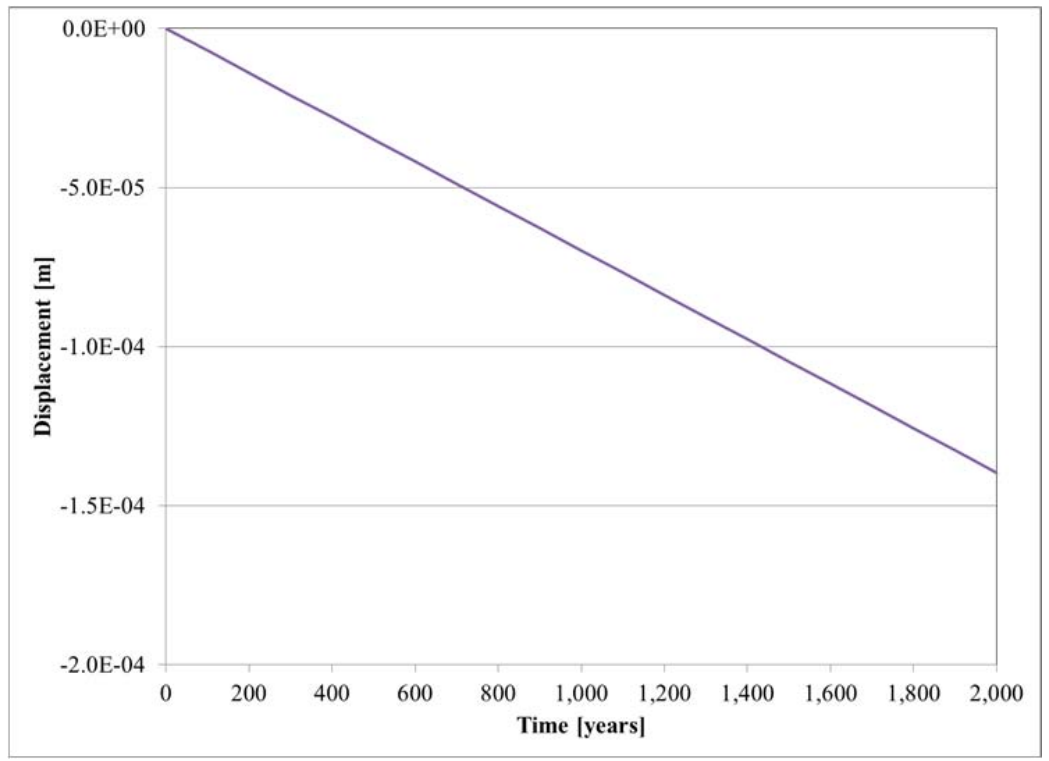

Figure 13. Thermal-viscous flow modeling, no heat generation, waste package vertical displacement versus time.

\section{SUMMARY}

In order to analyze the potential vertical movement of large, heat generating waste packages, coupled thermal-mechanical and thermal-viscous flow calculations using the Arpeggio, Adagio and Aria codes were conducted. All calculations show potential vertical movement on the order of $1 \mathrm{~mm}$ after 2,000 years. Further displacement beyond 2,000 years is predicted to be much smaller, except for the simpler thermal-viscous model. Even extrapolating the larger velocity from the thermal-viscous model, total displacement after $10^{6}$ years would be a fraction of a meter. With the more realistic M-D constitutive model, total displacement after $10^{6}$ years would be limited to a few millimeters.

\section{REFERENCES}

Batchelor G.K., 1967, An introduction to fluid dynamics, Cambridge University Press.

Munson, D.E., 1997, Constitutive Model of Creep in Rock Salt Applied to Underground Room Closure, Int. J. Rock Mech. Min. Sci. Vol.34, No. 2, pp 233-247. 
Potential Vertical Movement of Large Heat-Generating Waste Packages in Salt May 2013

This page intentionally left blank. 
Potential Vertical Movement of Large Heat-Generating Waste Packages in Salt May 2013

\section{Distribution}

Internal (Electronic Copy)

1 MS0836 M. J. Martinez, 1513

1 MS0779 K. A. McMahon, 6222

$1 \quad$ MS0747 $\quad$ D. J. Clayton, 6223

1 MS0747 $\quad$ E. L. Hardin, 6224

$1 \quad$ MS0747 $\quad$ R. J. MacKinnon, 6224

1 MS0899 Technical Library, 9536 
Potential Vertical Movement of Large Heat-Generating Waste Packages in Salt May 2013

(1) Sandia National Laboratories 